\title{
Ludwig Feuerbach, filósofo da linguagem? Um estudo de De Ratione, una, universali, infinita (1828)*
}

\author{
Ludwig Feuerbach, Philosopher of Language? A Study of De Ratione, \\ una, universali, infinita (1828)
}

\author{
José Edmar Lima Filho** \\ semedmar@yahoo.com.br \\ (Universidade Estadual Vale do Acaraú, Ceará, Brasil)
}

\begin{abstract}
Resumo: O objetivo desse trabalho é tratar da problematização filosófica da linguagem realizada por Ludwig Feuerbach (1804-1872) na obra De Ratione, una, universali, infinita (1828). Em que pese o fato da literatura especializada dificilmente enfrentar a importância desse tema no interior da contribuição teórica feuerbachiana, relegando-o a uma questão de segunda ordem ou raramente se referindo a ele como uma temática discutida pelo pensador, meu texto propõe a centralidade da linguagem para oferecer uma leitura alternativa de De Ratione, algo que efetuo com base no tratamento de alguns passos complementares, quais sejam, (i) do desafio de discutir uma questão semântica na compreensão feuerbachiana da questão, por meio do que insiro no debate certos aspectos de grande repercussão para o conjunto da construção filosófica de Feuerbach - como a questão do conhecimento, por exemplo -, e (ii) da insistência na realidade da compreensão dialógica do ser humano que tem por fundamento o problema da linguagem, algo que oferece significativas implicações para elementos vinculados ao domínio prático do pensamento feuerbachiano.
\end{abstract}

Palavras-chave: Ludwig Feuerbach; Keywords: Ludwig Feuerbach; language; linguagem; conhecimento; filosofia prática. knowledge; practical philosophy.
Abstract: This article aims at dealing with of language as a philosophical problem seen in his work De Ratione, una, universali, infinita (1828). Notwithstanding that the specialized literature hardly tackles the importance of this theme within the theoretical contribution of Feuerbach, consigning it to a second order issue or rarely referring to it as a question discussed by the thinker, this article, on the other hand, moves language to the center in an attempt to offer an alternative reading of De Ratione, something done based on the treatment of some complementary steps, such as, (i) the challenge of discussing a semantic issue in the Feuerbachian assessment of the problem, which led to the insertion of certain aspects in the debate considered as having great repercussion for the whole of Feuerbach's philosophical construction - such as the question of knowledge, for example - and (ii) the insistence on the reality of a dialogic understanding of the human being based on the problem of language, something that offers significant implications for elements associated with the practical domain of Feuerbachian thought. Ludwig Feuerbach's (1804-1872) assessment

* Essa publicação se insere no âmbito do Projeto de Pesquisa "Ludwig Feuerbach e a Linguagem", que conta com o aporte financeiro da Fundação Cearense de Apoio ao Desenvolvimento Científico e Tecnológico - FUNCAP/CE, por meio do Programa de Bolsas de Produtividade em Pesquisa, Estímulo à Interiorização e Inovação Tecnológica - BPI (Edital nº 02/2020).

** Registro meu agradecimento ao querido amigo Maximiliano Dacuy, pela generosidade da sua companhia e das observações cuidadosas ao escrito que agora apresento à apreciação pública para debate. Sem ele, a qualidade do trabalho estaria seriamente comprometida. Os deméritos que o texto comporta são de responsabilidade exclusiva do autor. 


\section{Introdução}

$\mathrm{Na}$ presente exposição me interessa investigar o tema da linguagem a partir de uma leitura de De Ratione, una, universali, infinita (1828), escrito que corresponde à tese para "habilitação à docência", como reelaboração da dissertação para obtenção do título de doutor em Filosofia, que se intitulara De infinita, unitate atque communitate rationis, do ainda jovem Ludwig Feuerbach.(cf. Tomasoni, 2011, p. 57-58). Redigido em latim, o texto está divido em vinte e três (23) capítulos curtos, agrupados em quatro partes que, embora tenham a intenção primeira de justificar a unidade, universalidade e infinitude da razão (evidenciada já pelo título), demonstrando a insuficiência de considerá-la uma faculdade ou propriedade individual - tal como seria a defesa de certa "filosofia vulgar" ali aludida -, trazem para o debate a centralidade do tema do conhecimento e concedem certo destaque ao problema da linguagem, de algum modo articulado com o conceito de pensamento expresso na obra, algo que por vezes é negligenciado mesmo pela literatura secundária especializada na interpretação da produção feuerbachiana.

Não é demasiado dizer que De Ratione permanece ainda um grande desafio para os estudos feuerbachianos no Brasil. Trata-se de uma obra pouco lida, não obstante sua importância para o conjunto do pensamento de Feuerbach, ${ }^{1}$ e, por isso mesmo, de um texto de pouca ressonância no cenário da pesquisa filosófica brasileira. Isso dito, justifica-se a importância de situá-lo brevemente em seu momento de constituição para, talvez, podermos alcançar com maior clareza a relevância de seu conteúdo.

É fácil encontrar elementos em De Ratione para situá-lo como um texto de inspiração hegeliana² (cf. Rambaldi, 1966, p. 182); nele, porém, se apresenta uma oposição à supervalorização do eu, acrescida de uma crítica subjacente à religião, pela qual Feuerbach se reconhece "discípulo direto [de Hegel,] que espera ter se apropriado, até certo ponto, do espírito especulativo de seu mestre” (Arvon, 1964, p. 3), mas, simultaneamente, confessa uma "assimilação livre" da filosofia de seu professor, com o fito de oferecer uma "realização”, “carnalização” ou “mundanização” da ideia ${ }^{3}$ (cf. Tomasoni, 2011, p. 58).

1 Rúa argumenta no sentido de que, em linhas gerais, em De Ratione Feuerbach constitui "as bases que fundamentam, em última instância, todo o discurso antropológico que caracterizará sua obra posterior", assim como "os fundamentos do que ele mesmo na carta Hegel chama a ensarkósis do puro logos, a carnalização de uma razão que deve presidir a vida pessoal dos homens e as relações entre os mesmos" (Rúa, 1995, p. 33).

2 Wartofsky chega mesmo a identificar uma leitura possível de De Ratione como uma "interpretação humanista" da Fenomenologia do Espírito hegeliana (cf. Wartofsky, 1982, p. 28).

3 Para recorrer ao conteúdo da Carta a Hegel escrita por Feuerbach, temos que, em De Ratione, o que se propõe é "um vestígio de filosofar a que se poderia chamar a realização e mundanização da ideia, a ensarcose ou a incarnação do Logos puro [...] trata[-se] da filosofia [...] não como um 
Apesar de centralizar a discussão em torno de certa concepção de razão, ${ }^{4}$ em que a linguagem parece representar uma temática aparentemente tangencial, à distinção de boa parte das interpretações convencionais de De Ratione, compreendo que o interesse de Feuerbach por uma abordagem filosófica do problema da linguagem merece realce por múltiplas motivações, entre as quais se destaca a antecipação, ainda que de modo muito preliminar, de um sem número de elementos que repercutem de forma bastante significativa para o conjunto de sua filosofia posterior, seja no que se refere ao tema do conhecimento propriamente dito, seja no que toca a questões do universo prático, como éticas e políticas, que são aprofundadas convenientemente no decorrer de sua produção intelectual.

Para a exposição da questão que proponho - e que aqui permanece sempre demarcada nos limites de De Ratione -, sugiro, em primeiro lugar, que comparece na obra em avaliação o enfrentamento de uma dificuldade semântica em relação ao tema da linguagem, a qual precisa se confrontar com o embaraço da (não-) designação dos singulares, restando a admissão de um elo entre nomes e o que Feuerbach chama de noções (notiones). Em um segundo momento, insisto que a problematização do assunto em análise abraça a necessidade de articulação com a questão do conhecimento, depois do que finalizo o meu argumento com as implicações da avaliação feuerbachiana da linguagem sobre o domínio prático de sua filosofia, particularmente sobre a ética, a política e, muito rapidamente, o direito.

\section{Linguagem: do problema semântico à fundação da comunitariedade humana}

A menção inicial ao tema da linguagem em De Ratione, una, universali, infinita (1828) aparece já no primeiro capítulo da obra. Ali, quando interessa a Feuerbach discutir a forma universal do pensar, comparece uma distinção introdutória imprescindível entre pensamento e sentidos/sentimentos, que reflete diretamente na sua abordagem sobre o tema da linguagem. Para o jovem Feuerbach, aos sentidos/ sentimentos se interpõem unicamente os singulares que povoam a natureza, ${ }^{5}$ dada

assunto da escola mas da Humanidade [...] trata-se então agora de fundar, por assim dizer, um reino, o reino da ideia, do pensamento que é consciente de si mesmo e que se contempla a si mesmo em tudo o que existe; [...] a filosofia [...] tem agora finalmente de conseguir que não subsista mais um segundo ou um outro, seja com a ilusão, o direito e a exigência a ser uma segunda verdade, como a verdade da religião, etc. [...] minha dissertação [...] mostra [...] um estudo filosófico e um esforço para a presentificação imediata de ideias abstratas" (Carta a Georg Wilhelm Friedrich Hegel [22 de novembro de 1828, GW, vol. 17, pp. 103-108 - uso aqui a tradução portuguesa de Serrão [2019, p. 244].).

4 Rambaldi procura resumir o conteúdo de De Ratione ao argumentar que "em um primeiro momento examina o pensamento abstrato e o pensamento que pensa a si mesmo, em seguida a unidade do pensamento e do pensado, para enfim concluir com a unicidade infinita da razão" (1966, p. 183), além de reconhecer um aspecto "intersubjetivo" presente na concepção feuerbachiana de "razão" incluída na obra.

5 Já em 1828 Feuerbach parece se interessar por uma tematização da natureza, tema que ocupará uma 
a limitação imposta por sua própria constituição, algo que the é inescapável. Ao contrário, o pensamento vem apresentado por meio de uma espécie de "vocação ao universal” graças à sua capacidade de abstração, pela qual the é possível superar a mera singularidade e ter em vista um horizonte mais abrangente por meio de representações genéricas.

Comfundamentonessadiferenciaçãoentrepensamentoesentidos/sentimentos, o jovem Feuerbach defende a inefabilidade das sensações, pois que estão sempre presas à singularidade individual, ${ }^{6}$ partindo da compreensão de que a comunicação só é possível com base na universalidade do que nomeia por "noções" (notiones), que são como que abstrações gerais realizadas por meio de uma capacidade imanente ao pensamento. ${ }^{7}$ De outro modo é dizer que a linguagem teria, como o pensamento, 0 predicado da universalidade, de tal maneira que apenas o pensamento poderia ser expresso por ela, não as coisas singulares presentes à exterioridade do sujeito ou mesmo as sensações privadas de um determinado indivíduo.

Utilizando-se da expressão latina notiones ${ }^{8}$ para apresentar a possibilidade de uma relação entre linguagem e pensamento, Feuerbach parece estar admitindo, fundamentalmente, que as coisas que pensamos estão conformadas e expressas na mente por meio de signos, o que é confirmado por algumas referências textuais de De Ratione (cf. Feuerbach, 1995, p. 94). Isso equivaleria a dizer que as "coisas pensadas" se distinguem quanti-qualitativamente das "coisas sentidas" por um motivo primordial: enquanto estas são singulares, aquelas são representações universais dos singulares na forma de conceitos ou, para usar a terminologia de De Ratione, de notiones. Claro que se deveria discutir como isso acontece ou como coisas singulares podem ter representações universais, para o que alguns elementos adicionais são requeridos à exposição.

Ao que parece, Feuerbach está assumindo previamente a tese de que as notiones universais são como que traduções mentais aproximadas hauridas da multiplicidade sensível por meio de uma potência inerente ao pensamento que, por sua própria natureza, é capaz de elaborar representações gerais por um

centralidade indiscutível ao longo de sua filosofia. As primeiras referências a ela em De Ratione são expressas do seguinte modo: "na natureza, pelo fato de que está sujeita aos sentidos e não pensa, não existe o gênero [...], não existe a planta, senão apenas plantas singulares de muitas formas" (Feuerbach, 1995, p. 90), o que significa que a sua concepção de natureza aqui está vinculada a uma ontologia de base que opto por nomear por "ontologia da singularidade", na qual o ser é concebido como que difundido nos singulares existentes (cf. idem, p. 91 - nota 16). Sobre essa "ontologia da singularidade" na obra de Feuerbach, cf. Lima Filho, 2019.

6 Wartofsky alude a isso informando que, em De Ratione, está em causa a "privacidade da percepção sensorial", o que justifica uma espécie de "imediatismo incomunicável” (Wartofsky, 1982, p. 31).

7 Que ao homem seja possível a abstração como um recurso do pensamento, Feuerbach o admite in verbis (cf. Feuerbach, 1995, p. 90-91 - nota 16).

8 Uma consulta ao latim permite compreender que notiones pode significar: (i) "Ação de conhecer (uma coisa), conhecimento, noção, ideia"; (ii) "Conhecimento de uma causa, investigação judicial, jurisdição, julgamento"; ou ainda (iii) "Sentido, significação, valor de uma palavra, noção, ideia, concepção" (Faria, 1962, p. 651). 
ultrapassamento da mera situacionalidade fática, dadas por algo como uma "reunião das semelhanças" ou "captação da essência por afinidade" entre os singulares. Essa posição, no entanto, permanece ainda muito mais no nível da pressuposição que da discussão propriamente dita em De Ratione, de modo que aqui ela não se encontra definitivamente elaborada; mas é razoável presumir que Feuerbach compreende a necessidade de aprofundamento dessa questão, pois em textos posteriores o tema é revisitado, como é o caso de Para a crítica da filosofia hegeliana (Zur Kritik der Hegelschen Philosophie [1839]) ${ }^{10}$ (cf. Feuerbach, 2012b, p. 36ss).

O avanço mais significativo do tratamento desse problema em De Ratione consiste na defesa de que as coisas que pensamos estão na mente "proferidas e comunicadas antes da comunicação mesma", pela qual se dá certo nome a elas (Feuerbach, 1995, p. 94). No limite, a afirmação feuerbachiana termina por indicar a aceitação de um paralelismo entre linguagem e pensamento ou, mais especificamente, entre nomes e noções, e, ao que tudo indica, admitindo uma preeminência lógica das últimas sobre as primeiras; ou seja, em De Ratione comparece desde cedo uma primeira dificuldade filosófica relevante no que toca ao problema da linguagem, de natureza semântica: trata-se, de fato, de questionar-se a respeito do problema da significação de um termo e de seu vínculo com a palavra. Pelo exposto, Feuerbach assume a hipótese de que o problema do significado de um termo não está dado por uma correspondência com os “dados externos ao sujeito" (pois as palavras não referem coisas singulares), mas com a representação genérica de seus elementos singulares construída pelo pensamento (já que as palavras referem conceitos [notiones]). ${ }^{11}$

A repercussão dessa hipótese não pode ser desvalorizada: com base no argumento precedente e ao definir que o pensamento é universal, do ponto de vista formal, e que, portanto, é ele uma espécie de "medida comum" entre os

9 A expressão foi recolhida de Serrão e é definida pela intérprete como segue: "o plano que se coloca é o da similitude (Ähnlichkeit) ou do parentesco (Verwandschaft), superador da alternativa entre a absoluta identidade e a absoluta diferença. Como os seres em geral, também os seres humanos nunca são iguais mas sempre diferentes, mas são para além das diferenças providos de notas características que lhes pertencem em comum com outros, dotados de propriedades e qualidades comuns que os convertem em similares ou parentes: 'Parentesco exprime o mesmo que identidade, mas a ele liga-se ao mesmo tempo a representação sensível segundo a qual os seres aparentados são dois seres independentes, quer dizer, sensíveis, existentes um fora do outro'. A filosofia que parte dos seres humanos para neles apreender estas semelhanças e similitudes processa-se na universalidade do comum, na universalidade da semelhança, e não na universalidade do idêntico. [...] Estes vínculos de parentesco serão os universais concretos" (Serrão, 1999, p. 144).

10 Para aprofundar mais adequadamente essa questão, cf. Lima Filho, 2019, p. 26-32.

$11 \mathrm{Em}$ suas Preleções sobre a Essência da Religião (Vorlesungen über das Wesen der Religion [1848]) a questão é retomada, entre outros momentos, quando Feuerbach argumenta que "assim como o conceito geral de pedra não é um conceito por assim dizer supramineralógico, um conceito que transcende o campo da mineralogia, não obstante sendo distinto do conceito de seixo, de cal, de espaço, não designando exclusivamente uma pedra determinada exatamente por compreender todas [...] assim [...] a palavra homem, não obstante abrangendo muitas espécies de homens, judeus, gregos, hindus, não é por isso um sobre-humano" (Feuerbach, 2009, p. 31). 
seres humanos, Feuerbach está a defender que a linguagem é também meio para a realização dessa "medida comum",12 ou, o que é o mesmo, está a demonstrar que a linguagem é a expressão da natureza intersubjetiva dos seres humanos ${ }^{13}$ da qual eles não se podem desvencilhar, posto que o homem "em nenhum momento pode despojar-se em absoluto de sua natureza pensante e partícipe da razão” (Feuerbach, 1995, p. 87). Por isso mesmo o jovem Feuerbach destaca que a linguagem humana não foi "inventada para fazer comuns as coisas que pensamos", pois o pensamento não se faz comum porque o exteriorizamos, senão, ao contrário, que o pensamento é comum por natureza e por isso mesmo pode ser exteriorizado, algo que equivale a admitir que a linguagem é sinônimo de um meio de expressão da potência natural do pensamento (cf. idem, p. 95), precisamente porque guarda uma identidade estrutural com ele ou algum tipo de isomorfismo. ${ }^{14}$

Essa posição “naturalista” de Feuerbach em relação à linguagem, entretanto, recupera pelo menos um apontamento metafísico interessante: ao sugerir que a universalidade requer, como sua condição de possibilidade, o uno, o outro e o vínculo entre eles, assim como identificar comunidade e unidade, Feuerbach pressupõe igualmente que a unidade do pensamento - que, no limite, coincide com sua universalidade - é o que torna possível à linguagem demarcar a natureza comunitária dos seres humanos. Isso significa que a linguagem é uma constante existencial indisponível ao arbítrio humano, assim como condição determinante de sua comunitariedade.

A consequência do exposto é a compreensão de que o homem seja capaz de ascender à unidade genérica, impossível aos animais em geral, em virtude de sua própria natureza interna; ${ }^{15}$ essa unidade, a que o jovem Feuerbach nomeia

12 Parece ser esse o sentido com base no qual Tomasoni defende que, para Feuerbach, a própria natureza do pensamento é linguística e dialógica (cf. Tomasoni, 2011, p. 67).

$13 \mathrm{Em}$ anotação de 1828 dos Fragmentos para caracterizar o meu Curriculum Vitae filosófico [Fragmente zur Charakteristik meines philosophischen curriculum vitae], escritos entre 1822 e 1844 (cf. Cesa, 1965, p. XIX), Feuerbach registra que "a manifestação sensível da infinita unidade e universalidade da razão é a linguagem. Não que a linguagem torne universal o pensamento: limitase a mostrar e a realizar aquilo que o pensamento é em si mesmo" (Feuerbach, 1965, p. 351).

14 Essa parece ser também a tese que, posteriormente, desenvolverá Wittgenstein, quando defende que há uma identidade formal entre linguagem, pensamento e mundo, o que permite que a linguagem seja concebida como representação, embora haja uma limitação interna à linguagem no que toca à possibilidade de representação dessa forma lógica. Daí dizer: "A proposição pode representar toda a realidade, mas não pode representar o que deve ter em comum com a realidade para poder representá-la - a forma lógica. Para podermos representar a forma lógica, deveríamos poder instalar, com a proposição, fora da lógica, quer dizer, fora do mundo" (TLP § 4.12), de modo que "o que pode ser mostrado não pode ser dito" (TLP § 4.1212). O mesmo é sustentar que "a proposição não pode representar a forma lógica, esta forma se espelha na proposição. 0 que se espelha na linguagem, esta não pode representar. 0 que se exprime na linguagem, nós não podemos exprimir por meio dela. A proposição mostra a forma lógica da realidade. Ela a exibe" (TLP § 4.121 - uso aqui a tradução ao português mencionada nas Referências).

$15 \mathrm{~A}$ anotação textual de Feuerbach é que o animal - "que por natureza não pensa - não chega ao extremo de ser e existir como unidade, senão que se dispersa cindido em indivíduos separados e excluídos unos dos outros" (Feuerbach, 1995, p. 87). 
"unidade verdadeira", ${ }^{16}$ corresponde à irredutibilidade do ser humano à pura e simples individualidade. A tese que está em causa é a de que, como vivente, o ser humano possui as características da natureza em geral (determinidade, concretude, historicidade situada, singularidade, etc.), mas como pensante - e, portanto, como dotado de linguagem - o homem é, simultaneamente, um homem indeterminado, geral, universal, pois que quando tenho consciência de mim como homem, "tenho abarcados em mim todos os homens" (Feuerbach, 1995, p. 88). Essa posição culmina na confirmação da persistência fundamental de uma espécie de dialeticidade natural intrínseca ao ser humano, posto que "sou universal como este homem, e sou referido às demais coisas como indivíduo determinado" (idem, p. 89).

Para confirmar as inferências derivadas desse primeiro exame, Feuerbach ainda trata de sugerir a aproximação hermenêutica entre pensar $e$ dizer quando assume haver uma "união de pensamento e linguagem”, não sem advertir que,

em termos gerais, a razão e a natureza do pensar deve ser posta sobretudo em que, sendo simplicidade, ela mesma é duplicidade. Por isso, nenhuma ação, nem de homens nem de coisas naturais, pode ser compreendida isoladamente, senão toda ela por certa associação e conjunção de muitas e diversas ações e forças que confluem em um mesmo ponto; uma ação qualquer é ela mesma certo múltiplo concurso de muitas ações; e deve-se ter em conta que também o pensamento é ação (Feuerbach, 1995, p. 92).

Por esse motivo, Feuerbach compreende que "o que pensa, ainda que na mais profunda solidão, não está solitário” (Feuerbach, 1995, p. 92 - nota 19), algo que impõe a necessidade de realizar como que uma "reformulação" do cogito cartesiano em uma direção dialógica e comunicativa ("penso, logo sou todos os homens" [idem, p. 127]) e afastar a possibilidade de aceitação de uma filosofia da subjetividade restritiva, solipsista e monadológica.

\section{Das potências da linguagem como medium: conhecimento, ética e política}

Além de estimular a compreensão de que há uma "união" entre pensamento e linguagem (cf. Feuerbach, 1995, p. 92), Feuerbach especifica essa unidade de uma maneira relacional, posto que a linguagem é tomada como uma espécie de “ponte" para a exteriorização do pensamento a outros (cf. idem, p. 94). Note-se, entretanto, que não se trata de dizer que a linguagem é apenas expressão de certa individualidade - o que de per si já seria muita coisa; postula-se que é ela também algo como um meio para a condução de mentes alheias, ${ }^{17}$ um veículo que permite

16 É curioso que, em A Essência do Cristianismo (Das Wesen des Christentums [1841]), Feuerbach retome essa unidade genérica para os seres humanos como justificativa daquela que seria "verdadeira vida", qual seja, a "vida comunicativa" (Feuerbach, 2012a, p. 92).

17 É o que, em Zur Kritik, Feuerbach tratará como "demonstração" (Demonstration) e "exposição" (Darstellung) (cf. Feuerbach, 2012b, p. 35-36). 
a outros seres humanos a execução de um percurso interno às suas próprias mentes para chegar à compreensão do que, por meio da linguagem, se quer significar. De outro modo é dizer que a linguagem pode ser concebida como meio por intermédio do qual se pode estabelecer o consenso ou mesmo o dissenso, pois, ao realizar esse percurso interno, cada qual pode assentir ou não às razões do interlocutor.

Não são pequenos os efeitos que essa concepção de linguagem pode alcançar e seu potencial não se restringe à esfera meramente cognitiva. Que haja subrepticiamente um problema epistêmico na consideração precedente me parece estabelecido sem maiores dificuldades: a condução de outras mentes por meio da linguagem permite que cada outro, a quem o discurso atinge, faça um percurso interno complexo, que envolve relações causais e uma intrincada cadeia de conexões e afastamentos, as quais acontecem espontaneamente na mente humana por comparações e pela presença de certos postulados lógicos irredutíveis - algo que, na minha interpretação, poderia corresponder, de algum modo, à admissão feuerbachiana de que haveria um aspecto formal universal no pensamento ${ }^{18}$ - , e realize uma série de inferências intermediárias para chegar, na outra ponta do processo, às conclusões sugeridas por meio da linguagem, tomada aqui como expressão de uma consciência alheia. Obviamente essas conclusões supõem que, considerando-se a ordem temporal do processo em análise, antes de hauri-las, eu, individualmente, não as tinha, embora pudesse tê-las - e por isso mesmo as tive! -, o que implica em um ganho cognitivo final em relação ao estágio inicial daquele processo mental. Esse é o aspecto epistêmico a que me refiro.

A minha suspeita, porém, é que a linguagem, compreendida nesses termos, além de realizar na vida concreta a essência comunicativa humana, e depois de permitir esse acréscimo cognitivo nos concernidos pelo discurso, faz que nela resida um enorme e inquestionável potencial ético-político, além de profundas implicações para o direito. Porque a essência humana está atravessada por esse elemento comunicativo, a vida coletiva, presente ao que nomeio por história situada, ${ }^{19}$ que não é mais que a historicidade concreta, é o locus para a realização efetiva do que Feuerbach concebe por “desejos naturais”. Tal como há no homem uma forte

18 Conforme o De Ratione, o "pensamento cognoscente [...] concebe as coisas sob certas fórmulas de pensamento" (Feuerbach, 1995, p. 100), o que indica que o pensamento parece ter leis internas fixas, que condicionam o conhecimento do ponto de vista formal - que haja tais fórmulas finitas e comuns do pensar que condicionem a concepção humana é repetido em Feuerbach, 1995, p. 104. Por isso mesmo, Feuerbach encontra a necessidade de apresentar uma composição dupla para a consciência: uma espécie de "pensamento autorreferencial" aliado a certa "forma universal do pensar", esta última anterior, necessária e não obtida pela experiência, não criada pela consciência ou por qualquer "pensamento subjetivo" (cf. idem, p. 102). Nesse sentido, a objetividade do pensamento (ou a forma universal que antecede a qualquer consciência singular) é o que torna possivel o compartilhamento do pensamento, algo que sugere a ocorrência de uma conaturalidade originária do pensamento entre mim e os outros homens do ponto de vista formal.

19 Sobre o conceito de história situada, cf. Lima Filho, 2019, p. 20-26. 
inclinação para o conhecimento das coisas, para alcançar a verdade, como algo inato (cf. Feuerbach, 1995, p. 109), cooriginária a isso seria a necessidade da vida compartilhada. Esse "necessitarismo" decorre da referência textual de que "tudo o que é princípio da natureza implica uma determinada necessidade" (idem, p. 110), o que significa que Feuerbach admite que a natureza é como que um "reino da necessidade". Deve-se considerar, entretanto, que

toda necessidade ocorre sempre entre duas coisas que, ainda que separadas e distantes, interdependam entre si tão intimamente que uma não possa estar sem a outra. Desta maneira, quando tenho sede ou fome, me sinto separado e distante daquelas coisas às quais estou unido por natureza, e precisamente porque estou naturalmente unido às coisas exteriores, as desejo e as apeteço. Pois se meu corpo não estivesse consorciado de forma natural com as coisas que deseja, não poderia sentir a dor de estar separado delas. Não pode, com efeito, se dar que no próprio desejo não esteja de alguma maneira a coisa desejada (idem, ibidem).

Daí decorre a importância de se estabelecer uma espécie de "tipificação dos desejos", para o que Feuerbach se serve de uma diferenciação entre os chamados "desejos fortuitos" e os "desejos naturais". De acordo com De Ratione, os "desejos fortuitos" são aqueles referentes às coisas "que não correspondem à nossa própria natureza e que são por si mesmos alheios a nós mesmos" (Feuerbach, 1995, p. 110 - nota 41); estão incluídos nesse grupo aqueles desejos por fama, honra, riqueza, etc. Neles, diz Feuerbach, "está separado o Poder do Apetecer", de modo que tais desejos não se podem reconhecer como "verdadeiras inclinações, verdadeiros impulsos" (cf. idem, ibidem). Em vez disso, os "desejos naturais" são equivalentes a "impulsos verdadeiros" ou "desejos verdadeiros", uma vez que surgem da nossa própria natureza (como é o caso do desejo de conhecer, definido como "aquele impulso pelo qual o homem tende e se esforça em superar-se e transcender-se a si mesmo como indivíduo" [idem, p. 12 - nota 45]) e, por isso, neles estão reunidos o poder e o apetecer.

Para voltar ao meu ponto, interessa que Feuerbach estabelece um vínculo indissociável entre os elementos que aqui em De Ratione são constitutivos essenciais humanos - embora por vezes se dê a impressão de que a razão da mente humana parece ser apenas uma instanciação da razão em geral, ${ }^{20}$ mas há que se investigar isso melhor (cf. Feuerbach, 1995, p. 99) -, com os quais a linguagem mantém uma relação indissolúvel, de modo que a existência real dos seres humanos é marcada por uma relacionabilidade irresistível, compreendida por meio de um vínculo comunicativo. Se é assim, então não resta mais que defender que Feuerbach antecipa, ainda no século XIX, a necessidade de refundar a ética e a política (assim como, por assim

$20 \mathrm{E}$ talvez por isso mesmo ele tenha tido o cuidado de rejeitar os equívocos, oriundos da nossa linguagem ordinária, que poderiam resultar de se considerar a razão como humana, uma vez que isso poderia gerar a compreensão de ela seria limitada, pois "a palavra homens pode ser empregada de maneira que não signifique mais que indivíduos" (cf. Feuerbach, 1995, p. 117). 
dizer, também o direito) pelo recurso à linguagem, algo que os manuais de História da Filosofia, em geral, sublinham acontecer sobretudo a partir do século XX em atenção a uma propalada "reviravolta linguística". ${ }^{21}$

Uma mostra disso pode ser recolhida da passagem de De Ratione em que, de maneira muitíssimo breve, Feuerbach traz à lume a questão da liberdade humana, que encontra na comunidade política concreta, regida pelo direito, a possibilidade de sua efetividade e realidade. Uma vez que os desejos naturais - exemplificados, entre outros, pela necessidade comunicativa constitutiva dos que ascendem à unidade genérica pelo pensamento - são como que uma "potência" ou mesmo uma "força", analogamente comparável à força gravitacional (cf. Feuerbach, 1995, p. 109), o ser humano é como que arrastado à vida comunitária para constituir um tipo de sociabilidade administrada por regras jurídicas, algo que impõe a cada indivíduo singular determinados "preceitos de obrigação pública” (idem, p. 89). Esse argumento vem amparado pelo jovem Feuerbach em uma espécie de "reconhecimento recíproco" entre os indivíduos humanos, em virtude de sua ocorrência como entes dotados da “medida comum” dada pelo pensamento. Para recorrer à letra de Feuerbach,

No fato, pois, de que tenho consciência, tenho abarcados em mim todos os homens, fora dos quais e junto aos quais eu estou posto quando sou reduzido a eles enquanto sujeito aos sentidos, isto é, como singular e como um em número; e deste modo aquilo que parece colocado fora de mim, na medida em que sou um ser sensível, está subsumido e dentro de mim na medida em que eu sei. Daqui surge o fato de que - por fazer ressaltar só isto dentre aquela infinidade das coisas humanas que a isto respeitam - sou livre, e vivo em uma sociedade regida pelo direito e pelas leis. Como eu os conheço a eles, eles me conhecem a mim, e não me distingo deles como algo diferente, que fosse de uma natureza distinta da deles. Assim, pois, tenho o mesmo direito que os demais, a mesma lei, os mesmos bens, a mesma pena estão estabelecidas para mim e para o outro; por esta razão, somos uma só coisa, ou melhor, para expressá-lo desta maneira e que assim se entenda: ainda que eu seja um singular, em mim não me ofereço eu apenas a mim mesmo, como um animal apenas se oferece a si mesmo, senão também ao outro, ao homem em geral, o que quer dizer que sou universal. Mas o direito deu o seu a cada um, o meu não é o teu nem ao contrário; assim, pois, o direito, ao unir, distingue e separa, e, ao remover diferenças, constitui e causa as maiores entre os homens; quer dizer, no direito sou universal na medida em que sou este indivíduo, ou seja, singular, não enquanto sou universal como o sou quando penso. $E$ isto mesmo vale para mim quando expresso, com meus costumes e minha vida, não a mim mesmo, senão aos preceitos da obrigação pública; ainda que eu seja universal no agir como deixando à parte todos os desejos de mim mesmo, e ainda que não siga mais que a vontade comum, contudo sou universal como este homem, e sou referido às demais coisas como indivíduo determinado (idem, $\mathrm{p}$. 88-89).

Pelo exposto, Feuerbach parece compreender que o domínio prático da reflexão filosófica, exemplificado aqui pelo apelo ético, político e jurídico do recorte, deve considerar os constitutivos fundamentais da essência humana para a 
razoabilidade de seus postulados, bem como para a legitimidade e aplicabilidade de seus princípios, o que demonstra uma intuição muito perspicaz para advertir sobre a necessidade de rediscutir filosoficamente os pressupostos da filosofia prática moderna e fazê-los transitar de uma perspectiva individual para uma transcendência imanente à comunitariedade constitutiva da natureza humana. Demonstra-se, assim, a insuficiência das pretensões modernas que se prendem a uma filosofia da consciência enclausurada no eu e a importância de empreender a encarnação da filosofia naqueles elementos que correspondem à realidade mesma do ser humano, algo que aparece aqui como projeto, mas a respeito do que Feuerbach jamais recuará em seus esforços de concretização.

\section{Considerações finais}

Da leitura que propus de De Ratione é possível perceber que não foi meu interesse apresentar uma visão geral da obra e, por isso mesmo, muitas questões importantes do escrito sequer foram sinalizadas, para o que outros estudos mereceriam ser realizados. Esse é, talvez, o ônus de uma pesquisa centrada em um ponto. Mas entendo que aí se encontra precisamente também a sua vantagem: em vez de levantar questões acessórias e permanecer à margem da densidade de um tratamento mais verticalizado de uma temática, meu propósito esteve sempre constituído por um rastreamento de uma questão normalmente negligenciada no tratamento da obra em análise, qual seja, uma abordagem filosófica da linguagem.

Como compreendo, minha inquietação por oferecer uma leitura alternativa de De Ratione permite, além de outras coisas, chegar a algumas conclusões importantes no que respeita ao tema que me propus avaliar, quais sejam:

(i) 0 jovem Feuerbach enfrenta uma dificuldade inicial quando assume, ainda que de modo incipiente, um problema semântico que deve ser considerado pela filosofia, ao apontar a dificuldade da designação dos singulares por meio da linguagem, que parece ter, como o pensamento, o predicado constitutivo da universalidade; isso traz à tona, além da já referida questão da linguagem, um debate importante sobre questões que respeitam à ontologia ou ao conhecimento, entre outras;

(ii) Que a linguagem pode ser considerada, por qualquer indivíduo singular, como meio para condução de mentes alheias, na medida em que é compreendida como ponte para a exteriorização do pensamento, algo que confere à linguagem a capacidade de favorecer certo alargamento cognitivo para os concernidos pelo discurso, que podem realizar um percurso de inferências similar ao do emissário para, ao final, assentir ou recusar o conteúdo de que ela é veículo; 
(iii) Em De Ratione o tema da linguagem é de tal modo discutido que, ao aproximar conceitualmente pensar e dizer, e manifestar que o pensamento é uma espécie de “medida comum” entre os seres humanos, acaba por se reconhecer um vínculo comunicativo como meio de expressão da natureza intersubjetiva humana;

(iv) Que a filosofia deve levar em conta a natureza comunicativa dos seres humanos para formular uma reflexão prática que condiga com suas especificidades e que, portanto, seja mais adequada a eles, longe da aceitação de um modo de filosofar preso à mera singularidade e fechado no contrassenso do solipsismo.

Pelo exposto, interessa discutir o tema da linguagem em Feuerbach como parte fundamental de sua filosofia, seja para aprofundar elementos que são externos à obra que aqui está posta sob as lentes, seja para promover uma consideração mais qualificada de seu pensamento, investigando como questões aparentemente laterais podem produzir efeitos bastante significativos para a verticalização das pesquisas sobre um autor ainda desconhecido na Academia, embora tenha tantas e importantes contribuições a oferecer ainda hoje a nós que pretendemos conhecer melhor a nós mesmos e ao que nos cerca.

\section{Referências}

Arvon, H. (1964). Feuerbach: sa vie, son oeuvre avec un exposé de sa philosophie. Paris: Presses Universitaires de France.

Cesa, C. (1965). Nota bibliografica. In: Feuerbach, L. Opere. Bari: Editori Laterza, p. XIII-XIX.

Faria, E. (1962). Dicionário escolar Latino-Português. Rio de Janeiro: Artes Gráficas Gomes de Souza S/A.

Feuerbach, L. (1965). Frammenti per caratterizzare il mio Curriculum Vitae filosofico. In: Feuerbach, L. Opere. Bari: Editori Laterza, p. 342-374.

Feuerbach, L. (1995). De Ratione, Una, Universal, Infinita. In: Feuerbach, L. Abelardo y Heloísa y otros escritos de juventud. Trad. cast. José Luis García Rúa. Granada: Editorial COMARES, p. 73-139.

Feuerbach, L. (2009). Preleções sobre a Essência da Religião. Tradução de José da Silva Brandão. Petrópolis: Vozes.

Feuerbach, L. (2012a). A Essência do Cristianismo. Tradução de José da Silva Brandão. Petrópolis: Vozes.

Feuerbach, L. (2012b). Para a crítica da filosofia de Hegel. Tradução de Adriana Veríssimo Serrão. São Paulo: LiberArs.

Lima Filho, J. E. (2019). Ontología de la singularidad y el problema del lenguaje en Ludwig Feuerbach: para una lectura de Zur Kritik der Hegelschen Philosophie (1839). Revista El Arco y la Lira. Tensiones y Debates. Buenos Aires, 7, 19-33.

Oliveira, M. A. (1996). Reviravolta lingüístico-pragmática na filosofia contemporânea. São Paulo: Loyola. 
Rambaldi, E. (1966). Le origini della Sinistra hegeliana. H. Heine, D. F. Strauss, L. Feuerbach, B. Bauer. Firenze: La Nuova Italia Editrice.

Rúa, J. L. G. (1995). Estudio preliminar. In: Feuerbach, L. Abelardo y Heloísa y otros escritos de juventud. Trad. cast. José Luis García Rúa. Granada: Editorial COMARES, p. 73-139.

Serrão, A. V. (1999). A Humanidade da razão: Ludwig Feuerbach e o Projeto de uma Antropologia Integral. Lisboa: Fundação Calouste Gulbenkian.

Serrão, A. V. (2019). A Carta de Feuerbach a Hegel. Revista Dialectus, 14, 235-247. DOI: https: //doi.org/10.30611/2019n14id41626

Tomasoni, F. (2011). Ludwig Feuerbach. Biografia intellettuale. Brescia: Editrice Morcelliana.

Wartofsky, M. W. (1982). Feuerbach. Cambridge: Cambridge University Press.

Wittgenstein, L. (1994). Tractatus Logico-philosophicus. Tradução de Luiz Henrique Lopes dos Santos. 2a . ed. São Paulo: EDUSP. 